\title{
Annular sarcoidosis mimicking granuloma annulare: a case report
}

\author{
Zafer Turkoglu ${ }^{1}$, Burce Can ${ }^{1}$, Ebru Zemheri ${ }^{2}$, Ilkin Zindanci ${ }^{1}$, \\ Filiz Topaloglu Demir ${ }^{1}$, Mukaddes Kavala ${ }^{1}$ \\ ${ }^{1}$ Department of Dermatology, Istanbul Medeniyet University, Goztepe Research and Training Hospital, Istanbul, Turkey; \\ ${ }^{2}$ Department of Pathology, Istanbul Medeniyet University, Goztepe Research and Training Hospital, Istanbul, Turkey
}

\begin{abstract}
Cutaneous sarcoidosis is a great imitator and we have to remember this mimicker also in the differential diagnosis of erythematous annular lesions. We report the case of a 50-year- old man with a 7-year history of erythematous, annular or serpiginous, scaly plaques on his scalp, forehead, preauricular region and around his mouth who was misdiagnosed as granuloma annulare.
\end{abstract}

Key words: Annular lesions; annular sarcoidosis; sarcoidosis.

S arcoidosis is a multisystemic granulomatous disease which frequently involves lungs with unknown origin, and characterized by hyperactivity of cellular immune system. Skin lesions develop in $25-35 \%$ of the patients with systemic sarcoidosis which are the first, and single manifestations of the disease $[1,2]$.

Lesions of cutaneous sarcoidosis which are called "Great Mimickers" are divided in 2 groups as specific lesions histopathologically manifesting typical sarcoid granulomas or nonspecific lesions demonstrating inflammatory signs [3, 4]. Papular and maculopapular lesions are the most frequently seen manifestations. In this article, a case of sarcoidosis with annular, archiform, and serpiginous lesions on face, and scalp is presented because of its rarely seen clinical presentation.

\section{CASE REPORT}

A 50-year-old male patient presented to our outpatient clinics with complaints of annular skin rashes on his face, and scalp which did not regress with previously administered topical therapies. His lesions emerged 7 years ago for which he consulted to other medical centers. He was then diagnosed as tinea facialis, and granuloma annulare, and treated accordingly. His personal, and family history was unremarkable except for long-lasting complaints of respiratory distress, and coughing. On dermatological examination, multiple archiform, serpiginous, erythematous, annular and partly squamous plaque lesions localized on face, scalp, and inner aspect of the ears were detected (Figure 1). Direct fungal examination of the material retrieved from lesions

Received: May 01, 2014 Accepted: June 09, 2014 Online: December 08, 2014

Correspondence: Dr. Filiz TOPALOGLU DEMIR. Istanbul Medeniyet Universitesi, Goztepe Egitim ve Arastirma Hastanesi, Dermatoloji Anabilim Dali, Istanbul, Turkey. 
could not reveal fungal elements. Histopathological examination of the biopsy material disclosed granulomas containing giant cells localized superficially within the dermis. The lesions were devoid of lymphocytes (naked granuloma) and concomitant necrosis (Figure 2). On laboratory analysis, ESR, CRP, serum calcium levels, calcium concentration in 24-hour urine, and angiotensin converting enzyme levels were within normal limits, while purified protein derivative test $(\mathrm{PPD})$ result was evaluated as anergic $(0 \mathrm{~mm})$. On chest roentgenograms, and thoracic computed tomograms, bilateral hilar lymphadenopathies were detected, and together with clinical, and histopathological findings, diagnosis of stage 1 sarcoidosis was made. Topical steroidal therapy was initiated for the patient with only pulmonary and cutaneous involvement, and he was included in our follow-up protocol.

\section{DISCUSSION}

Sarcoidosis is a multisystemic inflammatory disease characterized by noncaseified epitheloid granulomas whose etiology is not known completely. It has been conceived that in genetically predisposed individuals, multiple extrinsic antigens (microbial antigens, and environmental agents) induce hyperactivation of inflammatory pathways leading to sarcoidal granulomas [5, 6]. Most frequently lungs, lymph nodes, and skin are affected. Though skin lesions can emerge at any stage of the disease, usually naked granuloma is present from the onset of the disease.

In sarcoidosis, cutaneous manifestations are classified histopathologically as "specific", and "nonspecific" based on the presence or absence of typical granuloma. Specific lesions consist of macula, papula, nodule, plaque, subcutaneous nodule, infiltrated scar, and lupus pernio. Nonspecific lesions are erythema nodosum, ichthyosis, erythema multiforme, erythroderma, pruritus, calcifications, and Sweet syndrome $[6,7]$. Nonspecific lesions frequently emerge during acute phase of the sarcoidosis, and they are associated with good prognosis. Most frequently erythema nodosum is seen. Specific lesions have a more chronic course, and worse prognosis $[2,4]$.

Papular, and maculopapular lesions are the most frequently seen specific lesions. Generally, they demonstrate symmetrical distribution on eyelids,

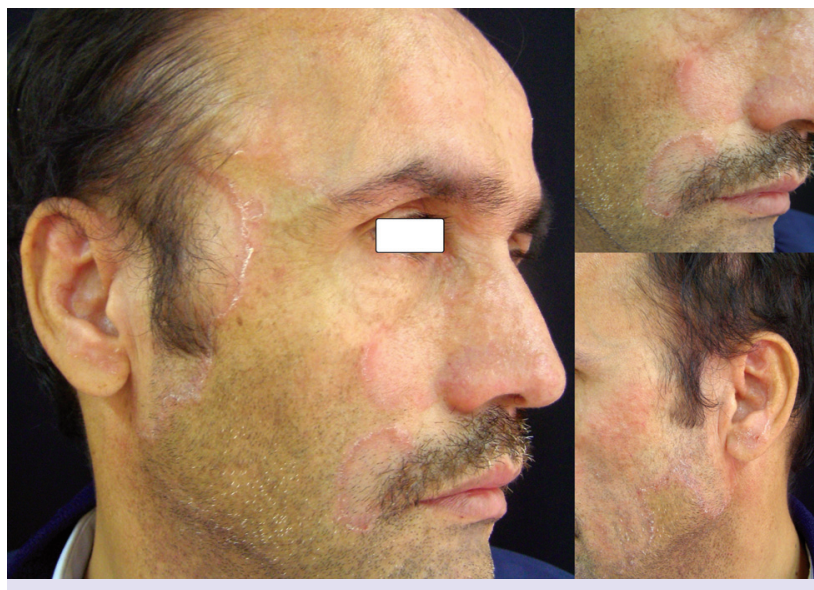

FIGURE 1. Archiform, serpiginous, and annular plaque lesions with patchy scales.

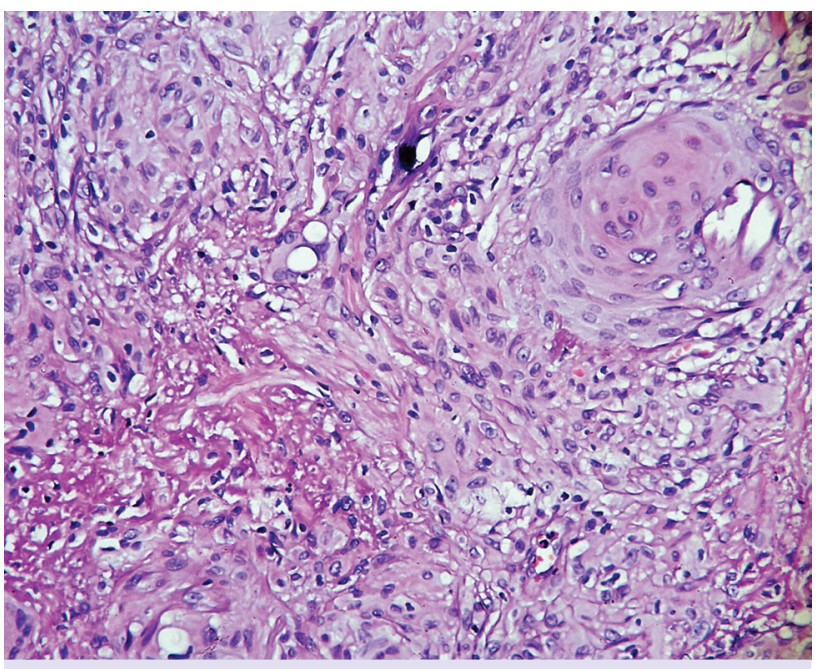

FIGURE2. Caseified granulomas containing epitheloid cells, and Langhans-type giant cells (H\&E x 40).

periorbital region, neck, and nasolabial sulci. In patients with sarcoidosis, rarely cutaneous involvement, erythroderma, keloid formation, angiolupoid, ichthyosiform, verrucose or annular eruptions have been reported [8]. As is seen in our case, in the differential diagnosis of annular, and serpiginous lesions localized on cutaneous regions exposed to sun light, priorly annular elastolytic giant cell granuloma, then granuloma annulare, fungal infections, lepra, subacute cutaneous lupus erythematosus, and eyrthema annular centrifugum should be thought $[4,9,10]$.

For the diagnosis of sarcoidosis, consistent clini- 
cal, and radiological findings together with presence of noncaseified granulomas in one or more than one tissues including skin, paratracheal lymph nodes, and salivary glands are required. All patients with skin eruptions should be evaluated as for systemic involvement of mainly lungs, eye, liver, and heart [10]. Classical histopathological findings in sarcoidosis comprise epitheloid histiocytes, and noncaseified granulomas rarely containing Langhans type giant cells. Typically, scarce number of lymphocytes, and inflammatory cells are seen on the periphery of a granuloma (naked granuloma)

During diagnostic procedures, one should not forget that these histopathological findings are not specific to sarcoidosis, and histopathologically in differential diagnosis, tuberculosis, atypical mycobacterial infections, fungal infections, reactions to foreign substances, and rheumatoid nodules should be taken into consideration $[7,11]$.

Histopathologically presence of granuloma, and characteristic features of granuloma facilitate the process of differential diagnosis, and as a clinical appearance, presence, and location of scales on the lesion have an utmost importance. In fungal infections, subacute cutaneous lupus erythematosus, lepra, erythema annulare centrifugum, squamae are observed, but they are not anticipated findings in granuloma annulare. In sarcoidosis, generally epidermal alterations are observed [12].

In conclusion, in sarcoidosis, annular and serpiginous lesions on the face are rarely seen. Since these lesions are evaluated as superficial fungal infection, annular elastolytic giant cell granuoloma, and granuloma annulare, diagnosis may be delayed for years. As seen in our case, sarcoidosis should be considered in the differential diagnosis of annular, archiform or serpiginous lesions localized on face, and the patients should be questioned as for potentially concomitant systemic findings.

\section{REFERENCES}

1. Newman LS, Rose CS, Maier LA. Sarcoidosis. N Engl J Med 1997;336:1224-34. CrossRef

2. Mañá J, Marcoval J, Graells J, Salazar A, Peyrí J, Pujol R. Cutaneous involvement in sarcoidosis. Relationship to systemic disease. Arch Dermatol 1997;133:882-8. CrossRef

3. Tchernev G. Cutaneous sarcoidosis: the "great imitator": etiopathogenesis, morphology, differential diagnosis, and clinical management. Am J Clin Dermatol 2006;7:375-82. CrossRef

4. Fernandez-Faith E, McDonnell J. Cutaneous sarcoidosis: differential diagnosis. Clin Dermatol 2007;25:276-87. CrossRef

5. Newman LS, Rose CS, Bresnitz EA, Rossman MD, Barnard J, Frederick M, et al. A case control etiologic study of sarcoidosis: environmental and occupational risk factors. Am J Respir Crit Care Med 2004;170:1324-30. CrossRef

6. Lazarus A. Sarcoidosis: epidemiology, etiology, pathogenesis, and genetics. Dis Mon 2009;55:649-60. CrossRef

7. Marchell RM, Judson MA. Chronic cutaneous lesions of sarcoidosis. Clin Dermatol 2007;25:295-302. CrossRef

8. Samtsov AV.Cutaneous sarcoidosis. Int J Dermatol 1992;31:38591. CrossRef

9. Harrison PV. The annular erythemas. Int J Dermatol 1979;18:282-90. CrossRef

10. Costabel U, Ohshimo S, Guzman J. Diagnosis of sarcoidosis. Curr Opin Pulm Med 2008;14:455-61. CrossRef

11. Tchernev G, Patterson JW, Nenoff P, Horn LC. Sarcoidosis of the skin--a dermatological puzzle: important differential diagnostic aspects and guidelines for clinical and histopathological recognition.J Eur Acad Dermatol Venereol 2010;24:125-37. CrossRef

12. Hsu S, Le EH, Khoshevis MR. Differential diagnosis of annular lesions. Am Fam Physician 2001;64:289-96. 